\title{
MASYARAKAT INDIA DAN PERJUANGANNYA SELEPAS PENDUDUKAN JEPUN DI TANAH MELAYU, 1945-1950
}

\author{
Shanthiah Rajagopal \\ Joseph M. Fernando
}

\begin{abstract}
The Indian community in Malaya faced a range of serious problems immediately after the end of the Second World War. War did not immediately bring much relief to the Indians rather it compounded some of the existing problems. Many of their leaders who were involved in the Indian Independence League (IIL) and the Indian National Army (INA) were imprisoned. This article examines the developments of the immediate postwar period between 1945 and 1950 to consider in some depth the nature of the problems faced by the community, drawing on primary sources and some personal memoirs which provide a revealing insight into the problems. In particular, this article examines the leadership problem, the issue of repatriation of labourers who were jobless, the conflicts resulting from low wages in estates and the work of the Indian Relief Committee in Malaya which with the aid of the Indian government sought to assist the displaced Indians. The article reveals how as a result of these severe problems faced by the Indian community, a few leaders led by John Thivy, began to plan and organise support for the establishment of an Indian political organisation to address the problems faced by the Indians. As a result of their efforts, the Malayan Indian Congress was formed in August 1946 and soon emerged as the dominant political organisations for the Indians.
\end{abstract}

\section{Pengenalan}

Pendudukan Jepun merupakan suatu peristiwa penting dalam sejarah Malaysia yang memperlihatkan kemunculan pelbagai gerakan 
nasionalisme di negara ini. Jepun telah memainkan peranan penting dalam penubuhan Indian National Army (INA) di Tanah Melayu yang merupakan sayap ketenteraan Indian Independence League (IIL) yang memperjuangkan kemerdekaan India dari penjajahan British. Oleh yang demikian, Jepun mula memberi tumpuan kepada segala bentuk gerakan kemerdekaan India bagi membebaskan India daripada penguasaan British.

Kedatangan Subhas Chandra Bose sebagai Komander INA telah mencipta satu sejarah baru dalam perjuangan INA. Subhas yang terkenal dengan gelaran Netaji telah memainkan peranan penting dalam penubuhan Provisional Government of Free India (Kerajaan Azad Hind) pada 21 Oktober 1943. Penubuhan kerajaan ini membolehkan beliau melancarkan perang ke atas British pada 24 Oktober 1943. Namun segala usaha ini berkecai dengan kekalahan Jepun pada 10 Ogos 1945 dan kematian Subhas dalam satu nahas kapal terbang pada 18 Ogos 1945. Setelah kemasukan British, askar-askar INA telah ditawan oleh British. Penahanan askar-askar INA ini telah membangkitkan semangat nasionalisme orang India di mana mereka mula memberontak demi pembebasan mereka. Keadaan ini membawa kepada campur tangan Kongres Kebangsaan India. Penglibatan Kongres Kebangsaan India telah banyak membantu dalam pembebasan askar-askar INA daripada menjadi tawanan perang British. Salah seorang tawanan yang berjaya mencipta nama selepas pendudukan Jepun ialah John Thivy. Beliau telah memainkan peranan penting dalam penubuhan Malayan Indian Congress (MIC) yang ditubuhkan pada Ogos 1946 untuk meneruskan perjuangan menentang penjajah dan mewakili masyarakat India di Tanah Melayu dalam semua perkara termasuk memperjuangkan kemerdekaan Tanah Melayu.

Langkah-langkah yang diambil oleh Kerajaan India berjaya menggalak dan membangkitkan semangat nasionalisme serta kesedaran berpolitik dalam kalangan masyarakat India di Tanah Melayu. Pertolongan dan perhatian yang diterima daripada negara India telah mendorong masyarakat India di Tanah Melayu untuk lebih cenderung ke arah negara India untuk mendapatkan perlindungan dan bimbingan. Ini merupakan salah satu faktor penting yang mempengaruhi aktiviti politik awal masyarakat India di Tanah Melayu selepas pendudukan Jepun.

\section{Masyarakat India di Zaman Pendudukan Jepun}

Pembentukan INA di Tanah Melayu berkait rapat dengan pendudukan Jepun. Imperial General Headquarters (IGHQ) Jepun telah memberi tumpuan kepada pembentukan Indian National Army (INA) untuk 
menentang British di India. Fujiwara Kikan telah dihantar dari IGHQ untuk mencapai matlamat tersebut. ${ }^{1}$ Fujiwara telah mengadakan hubungan dengan Pritam Singh ${ }^{2}$ dan menubuhkan Indian Independence League (IIL). Kejayaan Jepun mengatasi tentera bersekutu telah menyebabkan ramai askar tentera British India menjadi tawanan perang Jepun. Salah seorang tawanan perang yang telah mencipta nama ialah Jeneral Mohan Singh. Beliau telah diberikan galakan dan sokongan oleh Fujiwara Kikan dan Pritam Singh untuk menubuhkan satu pasukan tentera yang dikenali sebagai INA. ${ }^{3}$

Kejayaan Jepun menawan Singapura telah menambahkan lagi pertambahan saiz INA sebagai satu pasukan tentera yang mantap. Ucapan Jeneral Mohan Singh, Pritam Singh dan Fujiwara Kikan telah membangkitkan semangat nasionalisme kebanyakan askar tawanan perang Jepun berbangsa India yang pernah berkhidmat dengan tentera British India untuk menyertai INA. ${ }^{4}$ Diskriminasi yang diamalkan oleh pegawai-pegawai British terhadap askar-askar India dalam tentera British India telah menimbulkan rasa tidak puas hati dan mendorong mereka untuk menyertai INA. Jeneral Mohan Singh telah berjaya memimpin INA dengan baik sehingga timbul kepercayaan terhadap kepimpinan beliau. Askar-askar India dalam tentera British India mula menyertai INA kerana tiada diskriminasi dan ia juga dilihat sebagai satu cara yang lebih baik untuk melepaskan diri daripada penyeksaan di kem tahanan Jepun. ${ }^{5}$ Namun, matlamat utama mereka menyertai INA ialah bagi membebaskan tanah air mereka daripada penjajahan British.

Jeneral Mohan Singh telah memperkenalkan slogan 'do or die' untuk membangkitkan lagi semangat nasionalisme. Malah, latihan fizikal dan rohani telah diberikan kepada askar-askar INA. ${ }^{6}$ Hubungan antara INA dan IIL pada mulanya agak baik di mana IIL berperanan sebagai sebuah kerajaan dan INA pula berperanan sebagai sebuah pasukan tentera untuk kerajaan tersebut. Namun, hubungan baik ini tidak kekal lama dengan penubuhan Majlis Tindakan. ${ }^{7}$ Penubuhan majlis ini telah menghadkan kuasa Jeneral Mohan Singh sebagai Komander tunggal INA. Keadaan ini telah menimbulkan krisis antara IIL dan INA. Krisis ini berjaya diatasi dengan kedatangan Subash Chandra Bose yang lebih dikenali dengan gelaran Netaji. Netaji mula mengambil alih sebagai Komander INA menggantikan Jeneral Mohan Singh. ${ }^{8}$

Sumbangan Netaji yang begitu penting ialah usaha beliau dalam pembentukan Kerajaan Azad Hind pada 9 Julai 1943. ${ }^{9}$ Penubuhan kerajaan ini membolehkan beliau melancarkan perang ke atas British pada 24 Oktober $1943 .^{10}$ Netaji telah memperkenalkan slogan baru iaitu 'mara ke Delhi'. Askar-askar INA telah mara ke medan perang dan berjaya memasuki sempadan India pada 14 April $1944 .{ }^{11}$ 
Walaubagaimanapun, kegembiraan mereka tidak kekal lama kerana terpaksa berdepan dengan serangan yang hebat daripada tentera British yang mempunyai kelebihan dari segi tentera udara dan tentera laut. Malah, masalah kekurangan senjata, masalah penyakit, ketibaan musim hujan dan serangan hebat tentera British telah membawa kepada pengunduran tentera INA.

Kegagalan ini tidak menghancurkan semangat Netaji dan askaraskar INA. Netaji ingin melakukan serangan buat kali kedua ke atas British. Pada ketika itulah, Netaji mendapat tahu bahawa British sudah menguasai Rangoon yang membawa kepada kekalahan tentera INA dan Jepun. Maka, timbul persoalan di sini sama ada INA dapat meneruskan perjuangannya tanpa bantuan Jepun atau tidak? Menurut S. A. Ayer, Netaji menjelaskan bahawa pengunduran tentera Jepun tidak bermaksud pengunduran tentera INA. ${ }^{12}$ Kekalahan Jepun telah membawa kesan yang cukup mendalam kepada INA. Netaji telah mengadakan mesyuarat dengan Kabinet Kerajaan Azad Hind. Kabinet telah membuat keputusan agar Netaji bertolak ke Rusia atau Manchuria untuk mengelakkan beliau daripada menjadi tawanan perang Jepun. Walaupun Netaji tidak bersetuju dengan cadangan tersebut tetapi atas nasihat kabinet akhirnya Netaji bersetuju untuk bertolak ke Rusia. Sebelum bertolak beliau telah membubarkan IIL, INA dan kabinet Kerajaan Azad Hind. Netaji meninggal dunia dalam satu nahas kapal terbang pada 18 Ogos $1945 .^{13}$

Kematian Netaji merupakan satu kehilangan yang cukup berharga. Kematian beliau telah melenyapkan perjuangan INA. Setelah kemasukan British, askar-askar INA dan tentera Jepun telah ditawan. ${ }^{14}$ Penahanan askar-askar INA telah membangkitkan semangat nasionalisme orang-orang India di mana mereka mula memberontak demi pembebasan mereka. Keadaan ini telah membawa kepada campur tangan Kongres Kebangsaan India. Penglibatan Kongres Kebangsaan India telah banyak membantu dalam pembebasan askar-askar INA daripada menjadi tawanan perang British.

\section{Masalah-masalah Yang Dihadapi Selepas Pendudukan Jepun}

Masalah utama yang dihadapi oleh masyarakat India selepas pendudukan Jepun ialah penahanan pemimpin India atas tuduhan pengkhianatan kerana bekerjasama dengan Jepun semasa perang. Mereka yang ditahan merupakan pemimpin penting seperti pengerusi cawangan negeri IIL, ahli kabinet Kerajaan Azad Hind dan mereka yang berjawatan tinggi dalam ibu pejabat IIL. ${ }^{15}$ Antara mereka adalah N. Raghavan yang merupakan Presiden Central Indian Association of Malaya (CIAM) dan juga ahli dalam Majlis Tindakan IIL, S. C. Goho 
yang merupakan peguam dan juga ketua IIL cawangan Singapura, Dr. M. K. Lukshumeyah yang merupakan bekas presiden IIL serta J. A. Thivy yang merupakan peguam serta setiausaha kerajaan Azad Hind. Penahanan mereka telah menyebabkan masyarakat India kehilangan kepimpinan yang efektif. ${ }^{16}$ Oleh yang demikian, pembebasan mereka telah menjadi satu perkara yang penting pada ketika itu.

S. K. Chettur yang dilantik sebagai wakil India oleh Kerajaan India terpaksa berdepan dengan keseluruhan masalah yang dihadapi oleh masyarakat India di Tanah Melayu. Tumpuan pertama beliau adalah berkenaan isu pembebasan pemimpin-pemimpin India ini. Chettur telah mengadakan perjumpaan dengan Lord Louis Mountbatten, Komander Tertinggi Bersekutu. Menurut Chettur, mereka yang tidak bersalah di atas kekejaman atau penyeksaan harus dianggap sebagai 'pure collaborators'. Chettur menjelaskan kenyataan beliau sebagai wajar dan adil dengan menyatakan:

When a protecting power withdrew and left its erstwhile subjects to the tender mercies of an enemy occupying the country, (his) Government would naturally want to see that every legal defence open to (his) countrymen was raised on their behalf. ${ }^{17}$

Selain campur tangan Chettur, sekumpulan panel peguam dari negara India telah tiba di Tanah Melayu pada 12 Februari 1946 untuk membela pemimpin India yang ditahan. Namun, dapat dilihat keengganan pihak British untuk membawa mereka yang ditahan ke muka pengadilan. Hal ini demikian kerana perbicaraan di India akan menjadikan nasionalisme India lebih ketara dan juga menyebabkan sentimen anti-British meningkat. Perbicaraan di Tanah Melayu juga tidak dapat dijalankan kerana 'pure collaborators' bersama dengan Jepun turut melibatkan pedagang Cina dan Kerabat Diraja. ${ }^{18}$ Oleh yang demikian 'pure collaborators' dibebaskan tanpa sebarang perbicaraan dan ini sekali gus mengurangkan beban panel peguam yang tiba di Tanah Melayu.

Sejurus selepas pemimpin ini dibebaskan, masyarakat India berhadapan dengan masalah pemecatan jawatan dalam perkhidmatan Kerajaan. Masyarakat India yang diambil bekerja dalam sektor kerajaan dan Majlis Perbandaran semasa pemerintahan Jepun dipecat dan disingkirkan daripada perkhidmatan. ${ }^{19}$ Thivy dan beberapa pemimpin India lain turut berdepan dengan keadaan genting ini. Mereka menjelaskan bahawa tindakan penyingkiran merupakan satu hukuman yang tidak wajar akibat tindakan mereka menyertai IIL. Chettur sebagai wakil India diharapkan dapat menyelesaikan masalah ini. Chettur berjaya menyakinkan British dengan menyatakan, "....since 'pure collaborators' had been released, it was only natural and fair to reinstate 
those of the 'pure collaborators' who had been dismissed, to their respective civil appointments." ${ }^{20}$ Campur tangan Chettur berjaya menyelesaikan masalah ini apabila mereka yang disingkirkan diterima semula dalam perkhidmatan.

Penghantaran pulang orang India di Tanah Melayu ke negara India merupakan satu lagi masalah serius pada ketika itu. ${ }^{21}$ Kemerosotan industri getah selepas perang telah menyebabkan ramai orang India mula kehilangan sumber pendapatan. Orang India yang majoritinya bergantung kepada gaji harian di estet getah sukar untuk meneruskan kehidupan mereka dalam kos hidup yang tinggi dengan upah yang rendah. Oleh yang demikian, ramai orang ingin pulang semula ke India kerana bimbang dengan kehidupan mereka yang tidak terjamin.

Permintaan yang tinggi menyebabkan Chettur terpaksa menubuhkan satu Lembaga untuk mengatur proses penghantaran pulang mereka ini. Lembaga ini dikenali sebagai Lembaga Kepentingan yang terdiri daripada enam ahli yang dilantik. Chettur telah dilantik sebagai Presiden dan R. Jumabhoy yang merupakan Presiden Singapore Indian Chamber of Commerce pula telah dilantik sebagai Timbalan Presiden. ${ }^{22}$ Mereka yang ingin pulang ke negara India telah dibahagikan kepada empat kumpulan iaitu mereka yang sakit dan miskin, isteri dan anak yang kehilangan pencari nafkah, pulang atas urusan perniagaan dan mereka yang ingin melawat India. Chettur memberi perhatian khusus kepada mereka yang tidak mampu menampung kos perbelanjaan proses penghantaran pulang dengan memberi perkhidmatan secara percuma. ${ }^{23}$

Secara umumnya kos perbelanjaan yang terlalu tinggi telah membebankan masyarakat India pada ketika itu. Malah, L. R. Doraisamy Aiyar yang merupakan ahli dalam Majlis Penasihat ${ }^{24}$ dengan tegas menjelaskan keperluan dalam pengurangan kos perjalanan ini dan kepentingan meningkatkan kemudahan dalam perkapalan. Beliau menjelaskan bahawa kos perjalanan ke negara India adalah satu pertiga lebih tinggi daripada kos perjalanan ke Hong Kong walaupun jarak di antara negara India dengan Singapura dan Hong Kong adalah sama. ${ }^{25}$ Kadar perjalanan ini telah meningkat sebanyak enam kali ganda daripada kadar yang sedia ada sebelum perang. Chettur telah membuat perjumpaan dengan Malcolm MacDonald yang merupakan Gabenor Jeneral British di Asia Tenggara. Beliau telah membawa isu ini ke perhatian Pejabat Jajahan. Pada penghujung November 1946, pemotongan kos penghantaran pulang ke negara India telah dilaksanakan. Pada Februari 1947, tambang perkapalan ke Madras dari Singapura telah dikurangkan kepada $\$ 41.30$ daripada harga asalnya iaitu $\$ 154 .{ }^{26}$ 
Di samping itu, pemberian gaji yang rendah kepada buruh India di Tanah Melayu juga merupakan satu lagi masalah serius. ${ }^{27}$ Pekerja India selalunya dibayar mengikut gaji harian atau kadar masa. Manakala, pekerja Cina pula merupakan pekerja kontrak yang dibayar mengikut tugas atau hasil yang diperolehi. Chettur berusaha untuk mencapai kenaikan gaji sebanyak 100 peratus untuk pekerja India di Tanah Melayu. Penglibatan masyarakat India dalam IIL dan INA telah membawa kepada kemunculan kesedaran berpolitik dalam kalangan pekerja ladang. ${ }^{28}$ Persatuan-persatuan pekerja mula menuntut gaji dan kemudahan lain untuk pekerja ladang. Rusuhan merupakan tindakan terakhir mereka apabila tuntutan mereka ditolak selepas perundingan dengan pihak majikan. Oleh itu, Chettur telah memainkan peranan penting dalam menyelesaikan beberapa rusuhan dan pertelingkahan yang muncul akibat rasa tidak puas hati dalam kalangan persatuan pekerja berkenaan gaji dan kedudukan pekerja ladang. ${ }^{29}$

Chettur menjelaskan ketidaksamaan pembayaran gaji di antara pekerja Cina dan India dan mereka menginginkan kenaikan gaji sebanyak 100 peratus. Beliau menjelaskan bahawa pekerja India dibayar sebanyak \$1.15 (lelaki), \$1.15 (perempuan) dan 75 sen (kanak-kanak) ) $^{30}$ sedangkan purata gaji pekerja Cina ialah sebanyak $\$ 3.00$ sehari. Beliau berdebat demi memperjuangkan gaji pekerja India yang seharusnya dinaikkan sebanyak 100 peratus agar gaji mereka mencapai jumlah sebanyak $\$ 2.30$ sehari. Chettur telah mengadakan perjumpaan dengan S. B. Palmer yang merupakan Pengerusi United Planting Association of Malaya (UPAM). ${ }^{31}$ Namun, tuntutan beliau telah ditolak dengan alasan kejatuhan harga getah di pasaran dan kos pemulihan yang tinggi.

Chettur mula berkempen untuk kenaikan gaji pekerja India dan persatuan pekerja ladang mula bersatu menyatakan sokongan mereka kepada Chettur. ${ }^{32}$ Persatuan pekerja ladang mula berperanan sebagai wakil pekerja dan menyatakan dengan jelas tuntutan mereka terhadap kenaikan gaji pekerja. ${ }^{33}$ Wakil persatuan pekerja dari Johor, Pahang, Negeri Sembilan, Perak dan Selangor telah melancarkan rusuhan di seluruh Tanah Melayu pada 25 Ogos 1947 sebagai tindakan protes terhadap UPAM yang menolak kenaikan gaji sebanyak 100 peratus. ${ }^{34}$ Menurut laporan yang dikeluarkan oleh UPAM, sebanyak 70 peratus pekerja ladang di Tanah Melayu telah menyertai rusuhan. Di Selangor, Negeri Sembilan dan Melaka sebanyak 80-90 peratus pekerja telah menyertai rusuhan tersebut. ${ }^{35}$ Lanjutan daripada rusuhan tersebut, satu laporan Suruhanjaya Sementara Silcock ${ }^{36}$ berkenaan gaji pekerja ladang telah dikeluarkan. Laporan tersebut menjelaskan bahawa Suruhanjaya tersebut mengaku gaji yang diberikan kepada pekerja ladang tidak mencapai tahap yang mencukupi dengan keadaan ekonomi semasa. Namun, laporan tersebut juga menjelaskan bahawa tiada kenaikan 
dalam gaji pekerja kerana keadaan industri getah yang merosot selepas perang. Pengakuan Suruhanjaya Silcock berkenaan gaji yang tidak mencapai tahap memuaskan telah melipatgandakan perjuangan persatuan-persatuan pekerja ladang untuk menaikkan gaji pekerja. Kerjasama ini telah membawa kepada pembentukan National Union of Plantation Workers (NUPW) pada tahun 1954. ${ }^{37}$

Parti MIC yang ditubuhkan pada 1946 turut berjuang untuk kebajikan pekerja-pekerja ladang. Thivy yang merupakan Presiden pertama telah mengutuk tindakan UPAM yang melihat pekerja ladang sebagai hamba dan kuli. Beliau mendesak agar pekerja-pekerja ladang terus berjuang untuk menuntut hak mereka. ${ }^{38}$ Budh Singh, menggantikan Thivy sebagai Presiden MIC pada Ogos 1947 turut merakamkan sokongan beliau kepada pekerja India. Beliau turut mengutuk laporan Suruhanjaya Silcock dengan mengatakan, “...for the labour the policy is twofold; to battle for better economic conditions and to battle for better economic conditions and to battle for a better system of Government in the country". ${ }^{39}$ Beliau juga menegaskan bahawa:

... the struggle before you is twofold in nature. You must fight your local economic battles within the purview of your Unions for better conditions of life. At the same time you must also pull your weight with the Congress (MIC) in the major political battle for the introduction of responsible government in this country... Turn where you will laws will be passed against your interest in the name of law and order. You will be powerless for there will then be created in the country your greatest enemy- the unemployed labour reserve. How can you provide against such a state of affairs? only by having a hand in the government of the country, only by fighting for that form of democratic government which will return your worker representatives to the Central Legislature where they will protect the political rights of the workers. ${ }^{40}$

Selain itu, tuntutan Chettur dan persatuan-persatuan pekerja dikukuhkan dengan pelaksanaan larangan penghijrahan pekerja India ke Tanah Melayu oleh Kerajaan India pada tahun 1938. Usaha untuk menamatkan larangan penghijrahan pekerja India telah dilakukan namun, usaha tersebut gagal. ${ }^{41}$ Nehru mengatakan"...It is not intended to lift or relax the ban on emigration unless satisfactory conditions in respect of work, wages and status of Indian labourers are assured by the countries needing Indian labour." 42 Nehru telah menolak permintaan kerajaan Tanah Melayu pada penghujung tahun 1946 yang menghendaki tenaga buruh seramai 1500 pekerja dari India. ${ }^{43}$ 


\section{Langkah-langkah yang Diambil oleh Kerajaan India}

Lawatan Nehru ke Tanah Melayu pada Mac 1946 dengan jelas memberikan keyakinan dan harapan baru kepada masyarakat India di Tanah Melayu. Beliau telah menyampaikan rasa simpati terhadap kesusahan yang dihadapi oleh mereka dan memberi kata-kata semangat. Beliau juga turut menegaskan kesediaan negara India untuk membantu masyarakat India yang berada di luar negara dan tanggungjawab negara India dalam membela nasib masyarakat India. ${ }^{44}$ Nehru juga berjanji selepas kemerdekaan negara India dicapai, lebih banyak bantuan akan diberikan kepada masyarakat India yang berada di luar negara. ${ }^{45} \mathrm{Janji}$ Nehru telah memberikan satu keyakinan dan semangat yang tinggi kepada pemimpin India di Tanah Melayu.

Antara langkah penting yang diambil oleh Nehru ialah menubuhkan Indian Relief Committe in Malaya (IRCM) pada 26 March 1946. ${ }^{46}$ Beliau telah melantik Jawatankuasa Sementara di mana ahli-ahlinya terdiri daripada John Thivy, Dr. Lukshumeyah, R. Ramani, R. Jumabhoy, N. Raghavan dan Swami Satyananda. ${ }^{47}$ Thivy, Dr. Lukshumeyah dan Raghavan merupakan antara mereka yang dibebaskan hasil usaha Chettur dan panel peguam dari India. Pembebasan mereka jelas terbukti amat penting dalam usaha negara India memperbaiki keadaan masyarakat India di Tanah Melayu. Pemimpin-pemimpin ini telah memulakan perbincangan mengenai pembentukan sebuah parti politik untuk mewakili masyarakat India di Tanah Melayu. ${ }^{48}$

Pada April 1946, IRCM telah disusun kepada 18 cawangan dengan ibu pejabatnya terletak di Pejabat Kuil Sri Mariamman, Kuala Lumpur. ${ }^{49}$ Nehru telah melantik diri beliau sebagai Pengarah IRCM untuk memastikan beliau mempunyai hubungan yang rapat dengan Tanah Melayu dan mengawasi keadaan di Tanah Melayu dengan lebih teliti. ${ }^{50}$ Selain usaha IRCM, Chettur sebagai wakil India di Tanah Melayu juga telah menganjurkan beberapa bantuan kepada masyarakat India di Tanah Melayu. Beliau berjaya mendapatkan bantuan sebanyak 100,000 Rupee daripada Kerajaan India untuk membantu mereka yang kesempitan duit dan pertolongan dalam urusan penghantaran pulang ke negara India. ${ }^{51}$

Di samping itu, Chettur juga telah membuat permintaan kepada Kerajaan India untuk membekalkan kemudahan perubatan kepada pekerja-pekerja India di estet..$^{52}$ Hasil usaha beliau, Kerajaan India telah menghantar Government Medical Mission (IGMM) di bawah pengawasan Lt. Kolonel Shastri tiba di Singapura pada 22 Februari 1946. ${ }^{53}$ IGMM telah memulakan tugasnya di Selangor dan menubuhkan tujuh pusat perubatan dan meluaskan tugasnya sehingga ke negeri Melaka, Johor dan Negeri Sembilan. Pada penghujung Jun 1946, IGMM 
telah melawat 155 estet getah di Selangor, 96 estet di Negeri Sembilan dan 50 estet di Melaka. Sebanyak 42,000 pekerja estet dan keluarga mereka telah diberikan perkhidmatan perubatan dan 17,185 pesakit diberikan rawatan perubatan. ${ }^{54}$

Selain IGMM, kumpulan perubatan yang kedua tiba di Tanah Melayu di bawah pengawasan Dr. Solkar. Kumpulan perubatan ini dikenali sebagai Congress Medical Mission (CMM) ${ }^{55}$ Memandangkan IGMM memberikan perhatian kepada pekerja India terutamanya di estet getah, CMM pula terbuka kepada semua rakyat Tanah Melayu. ${ }^{56}$ CMM telah menubuhkan lapan pusat perubatan iaitu di Kota Bahru, Sungai Patani, Taiping, Telok Anson, Raub, Kuala Lumpur, Singapura dan Seremban. ${ }^{57}$ Sebanyak 122, 860 pesakit telah diberikan rawatan perubatan sepanjang tempoh masa dari 15 April sehingga 31 Julai 1946. Daripada jumlah tersebut, 19,770 orang Melayu, 20,618 orang Cina, 82,475 orang India dan 68 orang Eropah. ${ }^{58}$

\section{Peristiwa yang Membawa Perubahan Kepada Masyarakat India}

S. K. Chettur telah memainkan peranan penting dalam menyelesaikan masalah-masalah yang dihadapi oleh perkerja India di Tanah Melayu. Campur tangan beliau banyak membantu dalam menyelesaikan rusuhan yang muncul akibat tidak puas hati dalam kalangan pekerja India. Pada awalnya kedudukan beliau sebagai wakil India diterima baik oleh masyarakat India di Tanah Melayu. Lama-kelamaan keadaan ini mengalami perubahan di mana beliau mendapat beberapa kritikan daripada masyarakat India. Keadaan ini disebabkan oleh beberapa perkara seperti kenyataanS. K. Chettur di India bahawa tiada kebuluran di Tanah Melayu. ${ }^{59}$ Chettur juga didapati tidak berjaya menyelesaikan rusuhan di Sentul ${ }^{60}$ dan juga dituduh tidak mengambil berat dalam masalah penghantaran pulang pekerja India ke India. ${ }^{61}$ Malah, terdapat juga tuduhan yang menyatakan beliau tidak dapat menunjukkan semangat nasionalisme yang mendalam dalam mengatasi masalah yang dihadapi oleh masyarakat India di Tanah Melayu.

Pada 23 September 1946, satu mesyuarat telah diadakan dan keputusan telah dibuat untuk membuat permohonan kepada Kerajaan India agar melantik non-official untuk jawatan wakil India di Tanah Melayu. Keputusan tersebut dihantar kepada Nehru melalui parti MIC. Budh Singh yang mempengerusi mesyuarat tersebut menyatakan bahawa wakil India yang dilantik tidak harus menganggap mereka sebagai pegawai perkhidmatan awam dan sekaligus mengasingkan diri mereka daripada masyarakat kerana perbezaan kelas dan status. Beliau menjelaskan seorang rakyat India yang menganggap perkhidmatan 
awam sebagai tugas utamanya harus dilantik bagi menggantikan tempat Chettur. ${ }^{62}$

Segala tuduhan dan kritikan terhadap Chettur telah membawa kepada pelbagai reaksi dan respon daripada masyarakat India di Tanah Melayu. Malah, Chettur sendiri menjelaskan kenyataan beliau bahawa tiada kebuluran di Tanah Melayu adalah untuk mengelakkan kerisauan dan kebimbangan dalam kalangan ahli keluarga pekerja yang berada di India. ${ }^{63}$ Tuduhan Singapore Regional Indian Congress (SRIC) terhadap Chettur berkaitan masalah penghantaran pulang pekerja India juga mendapat respon daripada pelbagai pihak dalam kalangan masyarakat India. Swami Satyananda, ahli Jawatankuasa Kerja MIC dan Setiausaha IRCM, merupakan salah seorang yang terlibat secara langsung dalam proses penghantaran pulang pekerja India ke negara asal mereka. Beliau membantah tuduhan tersebut dengan menyatakan segala kritikan terhadap Chettur berhubung perkara ini adalah tidak wajar. ${ }^{64}$ Rencana pengarang dalam akhbar Tamil Nesan turut mengulas berkaitan isu ini dan mengkritik Presiden SRIC iaitu R. Jumbhoy kerana menyalahgunakan nama Chettur dengan kata-kata yang tidak berasas. ${ }^{65}$ Oleh itu, MIC telah mengambil tindakan disiplin terhadap SRIC kerana membuat tuduhan ini terhadap Chettur. ${ }^{66}$

Selain itu, persatuan-persatuan pekerja dan akhbar-akhbar India mula bertindak untuk membela Chettur. Pan-Malayan Estate Workers' Union (PMEWC) melihat Chettur sebagai pejuang kepada pekerja estet India yang miskin. PNEWC yang terdiri daripada 250,000 pekerja estet telah mendesak Nehru untuk mengekalkan Chettur sebagai wakil Kerajaan India agar beliau dapat meneruskan perkhidmatan beliau yang tidak terhingga kepada pekerja estet. ${ }^{67}$ Namun segala usaha ini tidak berjaya mengekalkan Chetur sebagai wakil Kerajaan India di Tanah Melayu. Chettur melepaskan jawatan beliau dan kembali ke India pada Ogos 1947. Akhbar-akhbar harian menerbitkan penghargaan terdapat perkhidmatan beliau yang cekap menangani masalah dan mengambil berat tentang kebajikan pekerja India. Kenyataan ini dapat dilihat dalam rencana pengarang akhbar Indian Daily Mail yang berbunyi:

\section{In the beginning of his term of office as the Repindia in Malaya, there was a lot of vehement criticism against him. Indians had even gone to the extent of demanding his recall. In due course, however, people began to learn for themselves the result of his quite and unostentatious services, performed in the face of great hardships and in the utter absence of facilities. The agitation naturally died down and opinion became current that Mr. Chettur had done his best and that no one could do better under the circumstances. ${ }^{68}$}

Thivy, Presiden MIC yang pertama telah dilantik sebagai pengganti Chettur. ${ }^{69}$ Perlantikan Thivy diterima baik oleh masyarakat India di 
Tanah Melayu kerana Thivy merupakan non-official dan nasionalis India yang terkenal di Tanah Melayu. Thivy meneruskan tugas Chettur sebagai wakil Kerajaan India di Tanah Melayu. Beliau menjelaskan bahawa "the prestige and status of Indians (in Malaya), no matter how highly placed a few of them may be, will be measured by the prestige and status of the vast majority of our nationals, namely the labourers." ${ }^{70}$ Thivy menerima perlantikan sebagai wakil India ketika beliau menjawat jawatan sebagai Presiden MIC. Walaupun perlantikan Thivy sebagai wakil Kerajaan India dianggap sebagai pilihan yang paling ideal, namun timbul kebimbangan berkaitan kepimpinan MIC. ${ }^{71}$ Thivy meyakinkan tindakan penerimaan jawatan sebagai wakil Kerajaan India dengan menyatakan "I could, with the help of the Government of India, serve the Indians better as Repindia than as the President of the MIC". ${ }^{72}$

Penggantian Thivy dan perkembangan politik semasa telah memperlihatkan perubahan secara beransur-ansur orientasi politik masyarakat India daripada terlalu memandang ke India dan mula memberi penekanan kepada aktiviti politik di Tanah Melayu. Sejurus selepas menerima perlantikan pada 6 September 1947, Thivy memberi ucapan yang berbunyi, "...we must stop the bird of passage attitude. We must give something to this country for posterity, something to remember us by." ${ }^{73}$ Ucapan yang mengandungi maksud yang sama diulangi semula oleh Thivy pada Disember 1947. Beliau menggesa agar masyarakat India menunjukkan kesetiaan dan kewajipan yang tidak berbelah bahagi kepada Tanah Melayu. Thivy juga menegaskan kepentingan dalam perubahan sikap masyarakat India yang hanya melihat Tanah Melayu sebagai tempat untuk mencari rezeki semata-mata. ${ }^{74}$

Dalam menjalankan tugas sebagai Repindia, Thivy telah berdepan dengan pelaksanaan darurat yang dikenakan pada tahun 1948. Thivy memainkan peranan penting dalam usaha membebaskan masyarakat India yang ditahan atas tuduhan menyokong pergerakan komunis. Beliau juga berusaha untuk mendapatkan pertolongan kepada ahli keluarga yang ditahan dan yang dibuang negeri. ${ }^{75}$ Peranan Repindia dalam mewakili masyarakat India di Tanah Melayu khususnya dalam perkara-perkara yang melibatkan pekerja ladang telah dihadkan selepas tahun 1949. Melihat kepada penglibatan Repindia dan Agen India yang aktif dalam masalah pekerja India telah menyebabkan Kerajaan Tanah Melayu membuat pemindaan terhadap Kod Buruh pada December 1949. Ini sekaligus menghapuskan kuasa dan kedudukan Repindia dan Agen Kerajaan India di Tanah Melayu. ${ }^{76}$ Sir Henry Gurney yang merupakan Pesuruhjaya Tinggi menjelaskan bahawa pekerja-pekerja India di Tanah Melayu harus mencari naungan politik di Tanah Melayu untuk menjaga dan menjamin kebajikan dan mengatasi masalah mereka. ${ }^{77}$ 
Pemindahan dalam Kod Buruh ini telah mengurangkan peranan dan kuasa Repinda dan Agen serta pengaruh Kerajaan India dalam segala isu masyarakat India di Tanah Melayu..$^{78}$ Keadaan ini jelas dengan lawatan Nehru ke Tanah Melayu buat kali kedua pada tahun 1950 sebagai Perdana Menteri Kerajaan India yang merdeka. Rencana Pengarang akhbar Indian Daily Mail dengan bersemangat menyatakan kedudukan Nehru sebagai Perdana Menteri India membolehkan beliau merealitikan jaminan yang diberikan ketika lawatan pertama beliau ke Tanah Melayu pada tahun 1946. Berikut adalah antara kata-kata beliau, "... when India becomes free, her hands will be long and powerful to protect each and every one of her children abroad". ${ }^{79}$ Namun segala kata-kata dan janji Nehru memperlihatkan perbezaan ketika lawatan kedua beliau ke Tanah Melayu sebagai Perdana Menteri Kerajaan India yang merdeka. Beliau menyatakan bahawa "Indians in Malaya must stand on their own feet. They should not look to India for any help; neither is India in a position to render any because she has her own problems to solve and her population to look after". 80

Kata-kata Nehru telah membawa kekecewaan dalam kalangan masyarakat India di Tanah Melayu yang mengharapkan perlindungan dan bimbangan daripada Kerajaan India yang merdeka. Keadaan ini telah membawa kepada satu perubahan yang penting dalam masyarakat India di mana mereka mula beralih daripada sikap terlalu memandang ke arah negara India. Pemimpin parti politik dan persatuan pekerja mula mencari naungan politik di Tanah Melayu untuk mencari penyelesaian bagi setiap masalah mereka dan demi kemajuan masyarakat India. Thivy yang merupakan pemimpin MIC yang paling disegani dan juga berkhidmat sebagai Repindia telah ditugaskan ke Mauritius sebagai Pesuruhjaya Kerajaan India. Beliau menyampaikan pesanan kepada masyarakat India yang berbunyi:

By virtue of your unstinting sacrifice, you have rendered yeomen's servies to Malaya in the economic sphere. Do not now vitiate it all, by adopting a stand in the political sphere, which could only be interpreted as an endeavour to perpetually keep planted your two feet on two different soils. The net result of such a shortsighted policy will be to suffer in the social sphere, all manner of discriminations. The invariable reason for the imposition of discriminatory laws or regulations, is fear and in the case of Malaya, it will be fear of disloyalty to the country as an outcome of divided allegiance. ${ }^{81}$

\section{Kesimpulan}

Zaman pemerintahan Jepun selama tiga tahun setengah telah meninggalkan kesan yang penting kepada perkembangan politik masyarakat India di Tanah Melayu. Kemunculan INA telah memberi 
impak yang penting dalam meningkatkan semangat nasionalisme masyarakat India. Namun, INA telah dibubarkan setelah kekalahan Jepun dan perjuangan INA turut lenyap dengan kematian Netaji. Perjuangan INA telah meninggalkan kesan positif kepada masyarakat India yang mula berfikiran kritis dan positif.

Secara kesimpulannya tempoh lima tahun bermula dari tahun 1945 sehingga 1950 merupakan satu tempoh yang amat penting dan bermakna bagi masyarakat India di Tanah Melayu. Tempoh ini boleh dikatakan sebagai 'formative years' bagi aktiviti politik masyarakat India di Tanah Melayu. Negara India dan isu-isu di India menjadi titik permulaan kepada permulaan organisasi politik dan aktiviti politik awal. Namun, peristiwa yang berlaku di Tanah Melayu dan India telah membawa kepada perubahan besar dalam masyarakat India di Tanah Melayu. Masyarakat India mula mencari naungan politik di Tanah Melayu untuk mewakili masyarakat India di Tanah Melayu dalam semua perkara. Hasrat mereka tercapai melalui peranan yang dimainkan oleh parti MIC sebagai salah satu parti politik utama yang bersuara demi kepentingan dan kebajikan masyarakat India di Tanah Melayu.

\section{Nota}

1 J. C. Lebra, Jungle Alliance: Japan and the Indian National Army, Asia Pacific Press, Singapore, 1971, hlm. 27.

2 Pritam Singh berasal dari Nagoke Sarli, daerah Lyallpur (Punjab). Beliau beragama Sikh dan telah datang ke Bangkok pada 11 April 1932 dan menjadi sami di kuil Sikh. Beliau sering mengadakan hubungan dengan golongan revolusioner India Timur Jauh. Beliau telah dilantik sebagai ketua IIL kerana beliau merupakan seorang individu yang mempunyai semangat nasionalisme yang cukup tinggi.

3 Sila lihat Paul Kratoska, The Japanese Occupation of Malaya, Allen and Unwin, St. Leonards, New South Wales, 1998.

4 Antara kata-kata yang telah menyedarkan mereka ialah 'Why fight for foreigners? Join us and fight for freedom'. Stephen Cohen, The Indian Army, University of California Press, Berkeley, 1971, hlm. 147.

5 Walaubagaimanapun, ini tidak bermaksud kesemua askar tawanan itu telah menyertai INA. Terdapat juga kumpulan yang masih enggan bekerjasama dengan INA kerana telah mengangkat sumpah taat setia kepada pihak British. The Malay Mail, 24 November 1945.

6 Tumpuan lebih diberikan kepada konsep perpaduan, kesetiaan dan pengorbanan. Konsep ini merupakan prinsip IIL iaitu 'unity, faith and sacrifice'. Jeneral Mohan Singh telah berjaya membentuk satu struktur pentadbiran yang sistematik bagi memudahkan urusan pentadbiran. Beliau juga telah berjaya membentuk satu sistem pangkat dan bayaran gaji yang lebih adil dan sistematik. A. C. Chatterji, India's Struggle for Freedom, Chatterjee and Co. Ltd., Calcutta, 1947, hlm, 41-42. 
$7 \quad$ Romen Bose, A Will For Freedom, V. J. Times, Singapore,1993, hlm. 18.

8 Rash Behari Bose yang merupakan ketua IIL begitu yakin dengan kewibawaan Subash dengan menyatakan 'Netaji is a born leader of leaders. I shall of course be quite pleased to ask him to take over from me.' H. N. Pandit, Netaji Subhas Chandra Bose: From Kabul to Battle of Imphal, Sterling Publishers Private Limited, New Delhi, 1988, hlm. 134.

$9 \quad$ Malai Sinpo, 23 Oktober 1943, hlm. 1

10 Harihara Das, Subhas Chandra Bose and the Indian National Movement, Sterling Publishers Private Limited, New Delhi, 1983, hlm. 270.

11 Kejayaan ini disambut dengan penuh kegembiraan oleh askar-askar INA. Menurut Harihara Das, 'Soldiers laid themselves flat on the ground and passionately kissed the sacred soil of their Motherland which they had set out to liberate.' Harihara Das, Subash Chandra Bose and The Indian National Movement, hlm. 290.

12 S. A. Ayer, Unto Him A Witness, Thacker and Co., Ltd, Bombay, 1951, hlm. 47.

$13 \quad$ Ibid., hlm. 59.

14 Antara mereka yang menjadi tahanan tentera British ialah John Thivy yang merupakan Setiausaha Agung IIL dalam Kerajaan Azad Hind. Beliau juga merupakan Presiden MIC yang pertama. Tamil Nesan, 21 September 1946.

15 G. P. Ramachandra, 'The Independence Movement in Malaya, 1942-1945', M. A. Thesis, Kuala Lumpur: Universiti Malaya,. 1970, hlm. 258. Penahanan pemimpin-pemimpin India ini telah menyebabkan pemimpin yang rendah pangkatnya untuk mengambil alih peranan tersebut Antaranya ialah, Amalu Akkiracanam yang merupakan Presiden Persatuan Pekerja India Selangor. Tamil Nesan, 17 Disember 1945. S. K. Chettur, Malayan Adventure, Mangalore: Basel Mission Press, 1948, hlm. 32.

Ramachandra, 'The Indian Independence Movement in Malaya, 1942$1945^{\prime}$, hlm. 258.

19 Tamil Nesan, 20 April 1946.

$20 \quad$ S. K. Chettur, Malayan Adventure, hlm. 98.

21 Pada April dan Mei 1946, hanya terdapat sebanyak 2000 tempat kosong dan pada Jun 1946 hanya terdapat sebanyak 1000 ruang untuk proses penghantaran pulang ini. Chettur telah memasang kabel kepada Nehru yang mewujudkan tambahan 3000 ruang lagi. Melalui usaha ini, sebanyak 20,000 orang India telah dihantar pulang ke India. Tamil Nesan, 22 Oktober1946; 20 November1946.

22 S. K. Chettur, Malayan Adventure, hlm. 33.

23 Chettur menjelaskan bahawa sebanyak $\$ 135,000$ telah dibelanjakan untuk memberi kos penghantaran pulang ke India secara percuma kepada lebih 1000 orang India. Tamil Nesan, 17 Januari 1947.

24 Selepas Pentadbiran British di Tanah Melayu, Kerajaan Malayan Union diperkenalkan dan Majlis Penasihat telah ditubuhkan untuk membantu Gabenor. Tiga ahli India telah dipilih dalam Majlis Penasihat ini. Mereka 
merupakan L. R. Doraisamy Aiyer, V. M. N. Menon dan H. H. Abdol Hamid Cader.

Malayan Union, Laporan Persidangan Majlis Penasihat (1946-1947), 29 Jun 1946, hlm. 58.

Kos tambang seorang sebelum perang adalah $\$ 19.50$. Tamil Nesan, 9 Julai 1946.

$27 \quad$ Semasa pendudukan Jepun di Tanah Melayu, pekerja India telah direkrut secara paksa untuk pembinaan landasan keretapi Burma ke Siam antara November 1942 hingga Oktober 1943. Daripada 74,000 pekerja India Selatan yang dibawa ke Siam dari Tanah Melayu, seramai 25,000 pekerja meninggal dunia, 12,000 pekerja pulang ke Tanah Melayu, 5,000 pekerja melarikan diri dan baki 32,000 orang hilang begitu sahaja tanpa sebarang berita. Keadaan fizikal dan tahap kesihatan mereka yang pulang begitu teruk sekali. Keadaan ini telah meninggalkan seramai 5,730 balu, 9,341 anak yatim. Sila lihat Charles Gamba, The National Union of Plantation Workers, Singapore, 1962.

Salah seorang yang mencipta nama ialah C. S. V. K. Moorthy yang menjadi Presiden Pan-Malayan Estate Workers Council. Indian Daily Mail, 13 September 1947.

Chettur telah meleraikan rusuhan di Estet Harvard pada Ogos 1946. Beliau juga turut mendamaikan rusuhan yang berlangsung selama enam minggu di Pelabuhan Pulau Pinang. Campurtangan Chettur dalam rusuhan di Estet Valencia di Pulau Pinang pada April 1947 telah membawa kepada penghentian rusuhan.Namun beliau tidak berjaya dalam menyelesaikan rusuhan yang berlaku di Sentul pada Mac 1946. Kesemua rusuhan ini berlaku akibat rasa tidak puas hati pekerja India dalam isu pemberian gaji yang rendah kepada buruh India di Tanah Melayu. Rusuhan merupakan tindakan terakhir mereka apabila tuntutan mereka ditolak selepas perundingan diadakan dengan pihak majikan..S. K. Chettur, Malayan Adventure, hlm. 33 Straits Times, 30 April 1946.

Indian Daily Mail; Straits Times, 30 April 1947. V. M. N. Menon turut menjelaskan ketidaksamaan pemberiaan gaji kepada pekerja India di ladang. Malayan Union, Laporan Persidangan Majlis Penasihat, 5 Mei 1947, hlm. 88.

33 Charles Gamba, The National Union of Plantation Workers, hlm. 18.

34 Indian Daily Mail, 23 Ogos 1947. Chettur sudah melepaskan jawatan beliau sebagai wakil India di Tanah Melayu pada Ogos 1947 dan kembali ke negara India pada ketika ini. Indian Daily Mail, 30 Ogos 1947. Rencana Pengarang yang bertajuk 'Strikes and more Strikes".

36 Indian Daily Mail, 2 September 1947. Suruhanjaya Silcock telah dibentuk pada 3 April 1947 di Tanah Melayu dan Singapura.

37 Ibid., Rencana Pengarang yang bertajuk "Eight Wonder of the Modern World", mengkritik laporan Suruhanjaya Silcock.

$38 \quad$ Indian Daily Mail, 31 Mei 1947.

39 Indian Daily Mail, 10 September 1947. 
$40 \quad$ Indian Daily Mail, 24 September 1947. Ucapan Presiden MIC, Budh Singh dalam persidangan Persatuan Pekerja India Negeri Sembilan pada 21 September 1947.

41 Pada tahun 1946, Kerajaan Tanah Melayu berusaha melalui misi Ahearne untuk berunding dengan Setiausaha Jabatan India Luar Negara untuk menamatkan larangan penghijrahan buruh India ke Tanah Melayu yang dikenakan pada tahun 1938. Namun, pada 26 Ogos 1946, kenyataan telah dikeluarkan bahawa selagi gaji yang berpatutan dan wajar dibayar kepada pekerja India di Tanah Melayu, tiada penghijrahan tenaga buruh yang baru dari India akan dibenarkan. Tamil Nesan, 30 Ogos 1946.

Indian Daily Mail, 31 Oktober 1946. Nehru mengumumkan kenyataan ini dalam Perhimpuan Perundangan India pada 29 Oktober 1946.

43 Tamil Nesan, 5 November 1946; 7 November 1946.

$44 \quad$ Tamil Nesan, 19 March 1946.

45 Ibid.,

46 Dana awal IRCM ini terdiri daripada hasil kutipan derma yang diberikan kepada INA ketika lawatan Nehru ke Tanah Melayu. Nehru juga mendapat jaminan daripada Lord Mountbatten bahawa dana yang dirampas daripada IIL akan diserahkan kepada IRCM. Indian Daily Mail, 25 June 1947.

$47 \quad$ Nehru turut menugaskan adik iparnya yang bernama G. P. Huttee Singh untuk mengkaji penubuhan IRCM. N. Raghavan telah dilantik sebagai Timbalan Presiden IRCM sementara R. Ramani ditugaskan untuk membentuk Lembaga Pemegang Amanah bagi IRCM. Thivy dan Swami Satyananda telah dilantik sebagai Setiausaha. Tamil Nesan, 29 March 1946; 18 June 1946; 13 Julai 1946.

48 Pemimpin-pemimpin ini telah terlibat dalam beberapa aktiviti reformasi. Antaranya penubuhan Hindi Veer Sabha pada April 1946 oleh 200 bekas ahli INA di Kuala Lumpur untuk membantu ahli INA yang hidup melarat. Keahliannya telah meningkat sehingga 1, 000 orang pada Julai 1946. Tamil Nesan, 31 Julai 1946. Malah, Jawatankuasa Pergerakan Pencegahan Minuman Keras juga telah ditubuhkan oleh Thivy, Bramachari Kailasam dan Budh Singh pada Jun 1946. Ahli-ahli dari CMM turut menghadiri mesyuarat tersebut. Bramachari Kailasam merupakan Ketua Publisiti IIL dan ahli Jawatankuasa Kerja MIC. Budh Singh telah dilantik sebagai Presiden Kedua MIC selepas Thivy turut memainkan peranan penting dalam beberapa aktiviti politik dan sosial pada ketika itu. Tamil Nesan, 26 Jun 1946.

$49 \quad$ Indian Daily Mail, 25 Jun 1947.

50 Indian Daily Mail, 28 March 1946.

51 Chettur menjelaskan bahawa sebanyak $\$ 112,950$ telah dibelanjakan oleh Kerajaan India dalam proses membantu masyarakat India di Tanah Melayu. Tamil Nesan, 17 Januari 1947.

52 Chettur juga telah membuat permintaan kepada Persekutuan Awam Madras, Jawatankuasa Kongres di Bombay dan Jawatankuasa Indian National Congress untuk menghulurkan bantuan pakaian kepada masyarakat India di estet. Sebanyak 423 bungkusan pakaian telah diterima 
oleh Chettur. Chettur melantik pegawai kebajikan di setiap estet untuk mengedarkan bungkusan. Malah, IGMM juga telah menghulurkan 10 bungkusan pakaian dari Madras. Tamil Nesan, 22 June 1946. Tamil Nesan, 22 Jun 1946.

Ibid., Lt. Kolonel Shastri yang merupakan pengarah IGMM telah memberi ulasan berkaitan perkhidmatan yang diberikan.

Tamil Nesan, 29 Mac 1946.

Tamil Nesan, 17 Mei 1946.

Tamil Nesan, 7 Ogos 1946.

Ibid.,

Sebanyak 30,000 pekerja India telah berkumpul di Kuala Lumpur dan menyampaikan keputusan mereka untuk mendesak Chettur pulang ke India kerana membuat kenyataan ini. Mereka berpendapat kenyataan Chettur tidak dapat membantu mereka dalam mendapatkan pertolongan dan rasa simpati daripada kerajaan India. Tamil Nesan, 1 Februari 1946. Seramai 3500 pekerja dari Klang dan Bangsar bertemu pada 15 Mac 1946 di Kuala Lumpur. Mereka menjelaskan bahawa Chettur gagal dalam menyelesaikan pertelingkaran tersebut dan mereka tidak akan mendapatkan bantuan daripada wakil India tersebut lagi. Tamil Nesan, 16 Mac 1946.

61 Singapore Regional Indian Congress (SRIC) mengumumkan pada 16 Julai 1947 bahawa mereka telah menghantar telegram kepada Nehru pada 20 Jun 1947 untuk mengarahkan Chettur pulang ke India. Indian Daily Mail, 11 Julai 1947. Setiausaha SRIC juga menjelaskan Chettur tidak mengambil berat kesusahan dan masalah yang dihadapi oleh masyarakat India berkaitan penghantaran pulang ke India. Indian Daily Mail, 29 Julai 1947, Laporan Tahunan SRIC yang diterbitkan dalam akhbar Indian Daily Mail pada 5 Mei 1948.

Tamil Nesan, 23 September 1946. G. Sarangapany yang merupakan editor akhbar Indian Daily Mail dan Tamil Murasu dan juga ahli dalam jawatankuasa kerja MIC menjelaskan bahawa Chettur merupakan seorang pentadbir yang berkebolehan tetapi masyarakat India di Tanah Melayu memerlukan seorang nasionalis India.

Chettur, Malayan Adventure, hlm. 45.

Indian Daily Mail, 12 Julai 1947. Swami Satyananda telah meletakkan jawatan beliau sebagai ahli MIC dan Jawatankuasa Kerja MIC tidak lama kemudian selepas insiden ini.

Tamil Nesan, 24 September 1947.

Indian Daily Mail, 4 Ogos 1947. Jawatankuasa Kerja MIC telah mengadakan perjumpaan pada 3 Ogos 1947 dan membuat keputusan untuk meminta penjelasan SRIC berhubung penghantaran kabel kepada Nehru untuk memanggil pulang Chettur ke India. MIC akan mengambil tindakan disiplin terhadap SRIC sekiranya penjelasan yang diberikan oleh SRIC tidak memuaskan.

Indian Daily Mail, 19 Julai 1947; Malaya Tribune, 18 Julai 1947; Jananayagam, 18 Julai 1947. Memorandum tersebut dihantar oleh Presiden PMEWC 
iaitu C. S. V. K. Moorthy. Thivy yang merupakan Presiden MIC telah dicalonkan sebagai pengganti Chettur. Tamil Nesan, 22 Julai 1947. Indian Daily Mail, 16 Julai 1947.

Chettur sendiri menjelaskan bahawa perlantikan Thivy adalah berdasarkan kepada kesesuaian politik semasa. Chettur, Malayan Adventure, hlm. 254. Indian Daily Mail, 16 Ogos 1949.

Indian Daily Mail, 17 Julai 1947; Tamil Nesan, 27 Julai 1947; Malaya Tribune, 29 Julai 1947; Malaya Tribune, 31 Julai 1947; Tamil Nesan, 16 Julai 1947.

Tamil Nesan, 2 Ogos 1947.; Indian Daily Mail, 5 Ogos 1947. Thivy menjelaskan bahawa masyarakat India yang tidak menyumbang dalam politik parti MIC tidak akan bersetuju dan menerima pendapat beliau sebagai presiden parti. Tetapi peranan sebagai wakil Kerajaan India menyebabkan beliau tidak ada batasan seperti ini.

Indian Daily Mail, 8 September 1947.

Tamil Nesan, 29 December 1947.

Tamil Nesan, 10 Februari 1949.

Laporan Persidangan Majlis Perundangan Persekutuan, Sesi ke-2, Mac 1949-1950, hlm. 597. Perdebatan di dalam majlis tersebut mendedahkan satu lagi sebab pemansuhan kedudukan dan kuasa Repindia dan Agen. R. Ramani yang merupakan ahli Majlis Perundangan Persekutuan membantah pemansuhan tersebut dan meminta untuk mengadakan perundingan dengan Kerajaan India. Beliau berpendapat bahawa kedudukan Agen dan Repindia di Tanah Melayu harus dikekalkan kerana telah diwajipkan dalam perjanjian yang dibuat ketika pertama pekerja India diambil untuk bekerja di Tanah Melayu. R. G. D. Houghton merupakan pegawai Kerajaan yang bertanggungjawab dalam isu pekerja menyatakan bahawa Kerajaan Tanah Melayu tidak ada lagi kewajipan untuk menerima Repindia memandangkan Kerajaan India sendiri yang mengenakan larangan terhadap penghijrahan buruh India ke Tanah Melayu pada tahun 1938. Misi Ahearne gagal dalam rundingan yang diadakan pada tahun 1946 untuk menamatkan larangan penghijrahan buruh tersebut.

Ibid.,

Indian Daily Mail, 26 December 1949.

Indian Daily Mail, 27 April 1949. Rencana pengarang yang bertajuk 'Malayan Indians Look for the Fulfilment of Nehru's Pledge'.

Indian Daily Mail, 26 Jun 1950. Rencana pengarang yang bertajuk "Pandit Nehru's Advice to Indians in Malaya". Masyarakat India di Ceylon juga diberi nasihat yang sama oleh Dr. B. R. Ambedkar yang merupakan Menteri Perundangan India. Indian Daily Mail, 18 Ogos 1950. 